\title{
Institutional Internationalization of Greenville University: An Empirical Analysis of its Motivations and Challenges
}

\author{
Yiwei Qiu ${ }^{1}$ \\ ${ }^{1}$ International Education College, Zhejiang A\&F University, Hangzhou, China \\ Correspondence: Yiwei Qiu, International Education College, Zhejiang A\&F University, Hangzhou, Zhejiang \\ Province, 311300, China.
}

Received: September 23, 2019

Accepted: October 30, 2019

Online Published: March 21, 2020

doi:10.5539/ies.v13n5p1

URL: https://doi.org/10.5539/ies.v13n5p1

\begin{abstract}
Drawing on case study evidence, this article explores the motivations a small liberal arts university internationalize and the challenges in facilitating internationalization. It employs qualitative methodology with qualitative data were collected from organizational documents, interviews, and field observations. The findings suggest that though a strong missionary is the most significant motivation for expansion, other internal and external factors impact the international decision-making process.
\end{abstract}

Keywords: internationalization, higher education, motivation, challenges

\section{Introduction}

Over the last two decades, internationalization of higher education has moved from the fringe of institutional interests to the very core of its mission. Internationalization is recognized in the Global Survey of Internationalization (Egron-Polak, 2011) as no longer being a luxury, and rather as an essential part of all university reforms. This has also been referred to as "the mainstreaming of internationalization" (De Wit, 2011a, p. 242). Knight (2004) defined the definition of internationalization as: "the process of integrating an international, intercultural or global dimension into the purpose, functions or delivery of post-secondary education" (Knight, 2004, p. 11). This definition sheds light on two features: one is that internationalization is intended to touch all higher education missions (teaching, research, and service); the second is the explicit preference for the integration of internationalization into existing institutional missions, rather than for it to be seen as something apart from or in addition to what HEIs do (Hudzik, 2015). These two striking features of the definition set the foundation and important groundwork for 21 st century evolving notions of internationalization.

\section{Literature Review}

\subsection{Motivations and Rationales for Institutional Internationalization}

An examination of the motivations and rationales for internationalizing the higher education sector is a complex task. Though motivations and rationales are not quite the same concepts, they are related and often used interchangeably. They help to explain, understand, or justify the reasons for actions (Hudzik, 2015). Individuals may agree with rationales as to why internationalization should be advanced without taking action, which can lay the intellectual foundation for the motivation to follow through (Hudzik, 2015). In this review, the motivations and rationales for institutional internationalization are regarded as interrelated and interchangeable. Traditionally, the motivations and rationales driving internationalization have been categorized as political, economic, academic, and social/cultural (Bostrom, 2007; Childress, 2010; de Wit, 1995, 2002; Knight, 2004, 2006b; Knight \& de Wit, 1997, 1999; van der Wende, 1996). In the past several years, much has been written about the changes in the motivations and rationales both within and between these four categories (de Wit, 2000, 2002; van Vught, van der Wende, \& Westerheijden, 2002). These generic categories provide a useful framework to analyze motivations and rationales both on the national and institutional levels; however, the significant changes in the nature and priority within each category need to be highlighted. For brevity's sake, this literature review concentrates primarily on the analysis of the emerging, important motivations and rationales driving internationalization at the institutional level.

The motivations and rationales driving internationalization are not mutually exclusive; rather, they are interrelated (de Wit, 2002; Knight, 1999b, 2004). They vary from institution to institution and shift in emphasis over time. This 
shift depends on internal organizational dynamics as well as environmental factors (Hudzik, 2015; Knight, 1999b). Significant world events in the 20th century such as World War I and II and the Cold War became instrumental motivators for political and higher education leaders alike to pursue internationalization efforts in tertiary education (O'Malley, 2015). Education and internationalization became avenues for both improving the image of a country, peace, mutual understanding, and for casting a country's policies in a favorable light (Alladin, 1992; Knight \& de Wit, 1995). After the Cold War, an emphasis-change from a political to an economic rationale became the dominant motivational force to internationalize higher education (de Wit, 1999, 2002; Knight, 1999b, 2004; Knight \& de Wit, 1995). There is a growing trend to view education in terms of an export commodity, rather than as a politically advantageous and benevolent endeavor (O'Carroll, 2012).

At the institutional level, the economic motivation to internationalize is becoming more prevalent as well. University entrepreneurialism is more dominant because of increased pressure to secure alternative forms of income in the face of heavily reduced higher education budgets (O'Malley, 2015). While the economic motivation to internationalize higher education is growing in strength, the cultural and social motivations and rationales appear to be of diminished importance and have received a relative lack of attention in the literature (Childress, 2009; de Wit \& Knight, 1999; Knight, 2004). It could arguably be attributed to their intangible benefits, as the attainment of intercultural competence is difficult to measure (Childress, 2010; Deardorff, 2012). Even so, since internationalization is an intrinsic component of the academic mission of universities (O'Malley, 2015), institutions continue to emphasize social and cultural rationales as reasons to internationalize. These include the enhancement of students' and faculty's cross-cultural knowledge and skills (Childress, 2010). Many observers contend that by making the commitment to prepare students to be global citizens, HEIs could ensure they achieve what is most meaningful and important in their internationalization efforts (Brandenburg \& de Wit, 2011).

Recently, Hudzik (2015) elaborated on the institutional motivations driving toward internationalization in a 21 st century context placing them into four primary categories. He refers to these as the core mission driver, the customer service driver, the social responsibility driver, and the globalization driver, covering virtually all aspects of most institutional missions (Hudzik, 2015). His exposition provides a different lens to understand motivations and rationales from the preceding demonstration in the literature.

All in all, which motivations and rationales an HEI decides to follow depend on the respective institution's history, resources, and stakeholder influences (Knight, 1994). A final point to emphasize is that, in spite of the complexity of individual rationales or a set of motivations, it is of fundamental importance for an institution to be very clear in articulating its motivations and rationales for internationalization, given that policies, programs, strategies, and outcomes are all linked and guided by explicit and implicit rationales (Knight, 2004).

\subsection{Challenges and Barriers to Institutional Internationalization}

While internationalization is strongly-supported rhetorically in contemporary HEIs, significant challenges and barriers to its institutionalization continue to exist (Childress, 2009; Hudzik, 2015). Some of the challenges and barriers are typical of any organizational change and some are particularly germane to internationalization (Hudzik, 2015). Most often, barriers to successful implementation are caused by funding, available resources (Green, 2003; Hser, 2005), standardization, quality, and equivalency in educational outcomes across different institutional types, delivery methods, and geographic locations (Alles, 2013). Also important in either impeding or supporting internationalization is institutional structures and cultures when an international initiative is implemented (Bonfiglio, 1999). These statements are verified by the IAU Fourth Global Survey of Internationalization of Higher Education (Egron-Polak \& Hudson, 2014), which queried a global sample of institutions regarding internal and external barriers to internationalization and identified 12 internal barriers and eight external barriers. Of the internal barriers, insufficient financial resources, limited experience/expertise of faculty, inflexible curricula, and bureaucratic impediments are among the top four. Of the external barriers, limited public funding, language barriers, difficulties in recognizing qualifications (from other countries), and visa restrictions on incoming students/staff and outbound student/staff are among the top four.

The reality of the loosely coupled internal structures and shared governance of institutional features of higher education present significant barriers to internationalization as well (Hudzik, 2015; Knight, 2006b; Weick, 1991). These include bureaucratic rules and regulations out of sync with cross-border, cross-cultural, and non-domestic activity; the absence of leadership; insufficient resources; institutional silos impeding collaboration; disconnection from key processes, such as budget planning, and so forth (Hudzik, 2015; Knight, 2006b). Internationalization as a process of institutional transformation requires coalition building and some degree of coordination for clarity of purpose and direction; however, the normal structure of the university does not lend itself to sweeping reform or centralized coordination (Aigner et al., 1992; Saat, 2007). 
In addition, internationalization itself has its own hurdles and challenges, including costs and competition for scarce resources and time, attitudes and personal discomfort with the notion of cultural and social differences, uncertainty avoidance, and the practical stage of preparing the grounds for the implementation of the internationalization process (Arabkheradmand et al., 2015; Hudzik, 2015). Furthermore, internationalization is increasingly viewed as "the white knight of higher education" (Brandenburg \& de Wit, 2011, p. 2), for it is claimed to be the last stand for humanistic ideas against the world of pure economic benefits allegedly represented by the term globalization. Effectively, this attitude exacerbates the devaluation of internationalization and the inflation of defensive measures. As a result, it poses a risk and creates a danger and barrier of self-depreciation and also makes internationalization unable to translate into improved quality or high standards (Knight, 2011). At the heart of these arguments lies a critical problem: as internationalization gains moral weight, observers become less focused on questioning or monitoring internationalization's effectiveness and essential nature, which ultimately is to improve the quality of education and research (Brandenburg \& de Wit, 2011).

Organizational and structural barriers are powerful in their own right, but particularly so if combined with behavior and attitude barriers to organizational change for internationalization (Hudzik, 2015). The behavioral, motivational, and attitudinal barriers at the levels of individuals, departments, and the institution as a whole also exert a powerful influence on the implementation of internationalization. These sources of barriers to internationalization are many. One categorization by Hudzik (2015) included: uncertainty without proof and fear of results; low tolerance for change and ambiguity; not being first; top-down is at odds with loosely coupled structures; the drag of mature enterprise; internationalization is "their" job, not mine; opposition and hostility from faculty and academic units, etc.

Given the challenges and barriers, leading researchers in the field of international education have increasingly called for a more reflective, iterative, and balanced approach to internationalization and also stressed the need for monitoring and evaluating internationalization initiatives. They also note the necessity to determine appropriate measures to track the progress and quality of the different elements and strategies of internationalization (Altbach, 2008; Knight, 2004, 2011; Robson, 2011). Knight (2009) also encouraged the international higher education community to remain vigilant to potentially negative and unexpected consequences, because the twists and turns along the road to internationalization can lead to unanticipated spin-offs and dire implications.

\section{Methodology Overview}

This study employed a qualitative instrumental case study methodology. Qualitative data were collected from organizational documents, interviews, and field observations and analyzed through the lens of motivations and challenges of institutional internationalization at Greenville University. It provides a multidimensional snapshot of internationalization at the university employing qualitative methods that gather great details from the following data sources: documents, interviews, field observations, and notes.

The paper focused on gaining insight from individuals directly involved in the internationalization process at Greenville University, IL, USA. Stakeholders from up and down the institutional hierarchy were interviewed to better understand their assumptions and perceptions of the internationalization phenomenon, especially the particular motivations and challenges to implement international programs at the university. In the process, insight was gained on why and how internationalization is unfolding at the institution. Such knowledge is a valuable addition to the literature as a scholarly contribution that provides greater understanding on common motivations and challenges to internationalization.

Understanding the concepts of internationalization, recognizing its motivations and rationales, and dealing with its challenges and barriers to organizational change are essential to moving from concept to action toward internationalization.

\section{Findings}

The findings are presented as thematic categories that emerged from data collected through nine oral and written interviews, 26 document analyses that were reviewed from over 40 documents collected, and 18 field observations.

In its early days, Greenville University was established under distinctive Christian influences, which included the mandate, given by Christ himself, to make disciples of all nations. Thus, the early impetus for contacting other peoples and cultures stemmed from the desire to spread the Christian faith. In 1924, for example, when an alumnus physician arrived in Peking to serve with a medical college, a student reporting the news observed: "In this way, the influence of our institution for God and Righteousness is being extended from year to year to the far corners of the earth" (The University Strategic Plan, 2016, p. 5).

Unsurprisingly then, the University's nascent internationalization began when its alumni became missionaries in 
different countries. At the time, however, internationalization was fairly one-dimensional and referred mostly to one-way mobility; its students and faculty travelling to other countries as missionaries. Over time, higher education began to focus more intently on globalization and internationalization. At the studied university, this trend manifested itself in a desire to bring the world to it so that students could interact and understand others and develop cultural awareness. This meant bringing international scholars and students to its campus. Along with the desire to spread the Christian faith, the desire to recruit international students was also linked to the search for tuition dollars in higher education in general, and also at this university.

Internationalization efforts at this university have grown over the past few decades. Various international initiatives and programs have been developed to bring international students to study at the university, to send its students to study/serve abroad, and to build credit articulation programs with overseas institutions. The institution has also increased its commitment to have a presence in Asia and South America and to increase the number of international students on campus. As the current President of the university noted in his interview:

The commitment to internationalization was really made through the last three presidents. President Smith [pseudonym] was particularly interested in internationalization of Africa. President Jones [pseudonym] began China initiatives, and then, under the [current] presidency, the university diversified its focus to even more countries, which added to the diversity of its campus.

A walk through the campus provided evidence of strategies being used to provide a global perspective. Numerous bulletin boards on campus display information about world cultures, global events, study-abroad opportunities, and global service learning and internships. The Japanese art gallery in the library and the Chinese art displays in an administrative building on campus further demonstrate the university's interest in world cultures. The University Pathways intensive English language program is also part of the university's global outreach. Meanwhile, the diversity of the students and faculty is celebrated in formal and informal ways. For instance, international students and visiting scholars enjoy a university-sponsored welcome dinner, and the University Pathways graduation ceremony is heralded and promoted as an important event on the campus. Faculty, students, administrators, and alumni support many of the multicultural co-curricular events.

The 21 st century is seeing a larger vision of internationalization emerging at the university with a more disciplined articulation of internationally relevant motivations and rationales, barriers and challenges, and more aggressive development of internationally supportive policies, support mechanisms, and international initiative and programs.

\subsection{Motivations and Rationales for Internationalization}

Motivations and rationales for internationalization at the university were identified through document analysis and the responses to the interview question: What are the major motivations and ultimate goals of internationalization at your university? This section discusses three motivations and rationales for integrating international dimensions into teaching, research, and service at the university.

\subsubsection{Expanding Influence on a Broader International Audience}

This investigation identified a number of motivations for internationalization at the university. Of these, expanding its influence on a broader audience appears to be primary. Indeed, this impulse to internationalize naturally flows from the university's heritage steeped in the education- and missionary-minded church from which it originated. As a senior faculty member stated in an interview:

Outreach was a key component of any Christian organization. If the university aims to empower students for the 21 th century and offer them a transforming education, it must provide them with knowledge and opportunities that go way beyond their limited cultural boundaries. It must move them from their small towns, from the mid-west mentality, from the U.S. perspective, and make them citizens of the world.

The generations of its graduates have been involved in some form of Christian ministry across the United States and around the world. The impetus to expand and formalize this outreach is a key motivator for the institution's internationalization efforts. The current President emphasized that the Greenville University agenda to extend its heritage and expand its reach was necessarily ambitious and particularly challenging against the backdrop of this fast-changing world where people are more globally aware, interconnected, and technologically driven than ever before.

Some of the interviewees echoed the President's ideas and identified the motivation to internationalize as "sharing the Gospel," a desire to spread the "good news" to all peoples. Thus, it seems that a primary motivation to internationalize is rooted in the faith-based mission of the university. 


\subsubsection{Enhancing Quality of Teaching and Learning}

The second pressing motivation for the university's internationalization is related to educational goals, notably to ensure students gain global awareness, to enhance educational quality, and to expand students' intercultural expertise. Indeed, some critical documents and all of the interviewees recognized strengthening the international awareness of students and improving the quality of teaching as a strong (if not the strongest) motivation to internationalize. Thus, the university is committed to cultivating innovation and agility by "emphasizing learning beyond the classroom by enhancing the educational experience with service learning, mission trips, international experiences, chapel and worship activities, athletics and major-focused internships that help students develop their minds, bodies and spirits" (The University Strategic Plan, 2016, p. 7). In addition, the institution has developed a plan to develop new academic programs, facilitate shorter degree completion times, emphasize learning beyond the classroom, deliver a transformational first year experience for students, and increase its international reach.

Several interviewees acknowledged the need to internationalize and to be active in the international arena and asserted that international initiatives would make the university's future brighter and benefit students and faculty members. As one department chair noted:

The university was to deliver a quality higher educational experience to its students within the broader multi-cultural context, not only of our society but of the world. Its mission was not to have a parochial education that was locked into a particular culture but very wide and open-ended education that opened the world to our students.

A senior administrative officer, in turn, affirmed:

Internationalization of the university dramatically improved the educational milieu and broadened the recruiting market. Students with an international perspective of any intensity should be expected to be better empowered and aware to effectively serve in their workplace and community after college. The wake-up experience of seeing and knowing the international landscape seemed to cause students to move from extrinsic motivation to learn to intrinsic motivation. Research showed that students who traveled abroad retained and graduated at a much higher level than those who did not.

These ideas were echoed by a faculty member who remarked that: "It was significant for the university to maintain and to foster or to enhance international cooperation so that it could educate good global citizens and promote democracy worldwide."

Interviewees also noted the importance of increasing the diversity of students and faculty in order to expand faculty and student perspectives (Green \& Olson, 2003). One faculty member emphasized this point: "The faculty was very much strengthened when it built cooperation on a worldwide level. It gave you perspectives for solving problems by having access to people from different countries who speak other languages and having access to other publications." Another senior faculty member stressed the impact of internationalization on students' thinking:

Internationalization at the university meant opening up the minds and hearts of its students to the wide differences of cultures and beliefs of the people in our world today. It meant that we made effort not only to present this information in theory, but also to provide opportunities for the students to experience living and working in different cultures first-hand. It meant that all faculty members include information in their courses about how different cultures might approach certain subject matter. An international campus would encourage professors and students to do research on different aspects of global impact in their own lives.

One department chair praised internationalization at the university as "it enabled the university to expand and diversify its student base which affected not only those international students who were having an experience in America. It also affected American students as they learned to interact with students from other cultures." All of these reasons motivated the university to internationalize, and as a result, to enhance the quality of teaching and learning.

\subsubsection{Diversifying Revenue Generation}

Revenue generation was another one of the prominent motivators for the university's internationalization efforts. In this, it was consistent with literature that highlighted a growing trend in the international higher education arena, with government and university leaders increasingly viewing education in terms of an export commodity (O'Carroll, 2012). Tuition and fees from international students are obvious attractions to many institutions (Hudzik, 2015). 
Before elaborating further on this significant motivating factor, a brief review of the historical context behind the university's various sources for income is merited. One interviewee noted that for nearly all of the university's existence, the university had been self-sufficient and relied mostly upon internally generated income (tuition generated each year). However, as one university senior faculty noted, "In the past few years the university had been suffering an economic set-back." In light of this challenge, she explained that: "In the last six years the top administration [president and some members of his cabinet] realized that the sustainability of the school depended on reaching out to a different population, i.e., international students, to generate new revenue."

With this economic motivation as a key influence in the university's directive to internationalize, the institution developed a number of lofty goals outlined in its internationalization strategic plan, including increasing the number of international students. The university, and many institutions worldwide have followed the simple logic that, "the more foreign students there are paying high tuition fees, the higher the economic return" (de Wit, 2002, p. 91). Interviewees for this study were not very candid about the impact the economic climate and its own financial status had on its approach and goals for internationalization; however, they recognized that the bleak economic context was a major factor that compelled the university to pursue opportunities to generate much-needed revenue. All participants for this study expressed some understanding of the motivation to generate funds from institutional internationalization, even though they did not emphasize this motivation partly due to self-esteem and partly due to a belief that might consider money-making as something ignoble as compared to education. One academic noted, however:

I believe in the monetary aspect as well. We understood that international education was big business, and students from other countries would pay dollars to come to American universities. Well, that was fortunate for us. Our mission was furthered by the monetary possibilities of having students come and pay for an education.

Most interviewees recognized this motivation, but in vague ways. They, for instance, described this motivation to expand the number of international students as "the need to enroll more students since the university was struggling to find students to fill their classrooms," and "to broaden the recruiting market." Only one noted openly, "Most of our evaluation of international programs was based on income generated." The notion that internationalization is driven, at least in part, by the need for revenue finds support from the reality that in evaluations of internationalization efforts at the university, financial impact was always the main measure to assess the achievement of international projects. For instance, annual/periodic revenue and cost are used as the primary index to assess the achievement of international student recruitment.

In summary, the university's commitment to missionary work continues to have an impact on its decisions and motivations to internationalize. Moreover, its motivations to internationalize tend to cluster around desired educational outcomes and revenue generation. Even though categorizing motivations suggests a certain degree of separateness and individuality among them, these categories are interconnected and cross-feeding (Hudzik, 2015). Institutional internationalization is better viewed as part of a cause-and-effect chain (perhaps a matrix) of motivations, challenges, approaches, and purposes. To move beyond motivations and rationales to action, and then to results, it is also important to identify and reduce barriers and challenges to internationalization.

\subsection{Challenges and Barriers to Internationalization}

The university's challenges and barriers to internationalization were identified through the analysis of responses to the following interview questions: What do you think has been your university's significant barriers and challenges with respect to the internationalization process? This section is dedicated to discussing the challenges and barriers the university faced in the process of integrating an international focus into university structures and functions.

\subsubsection{Cultural Traits as Barriers}

For the purpose of this study, university culture was conceptualized as the organization's territories, history, characteristics, core values, and relationship to the broader socio-political system in which it exists today. Cultural traits as obstacles inhibiting internationalization at Greenville University include a deep-rooted and strict Christian culture, a lack of self-confidence about branding, a remote geographic location, and a wait-and-see attitude toward internationalization. As noted above, the university's history and culture provided an impetus to internationalization. Interestingly, the same history and related cultural traits created some internal barriers to internationalization in the form of behavioral and attitudinal barriers at the level of individuals, departments, and within the institution as a whole. Some of these were rooted in some faculty and student lifestyle regulations. For instance, the university encourages a healthy campus by prohibiting smoking, drinking, and using illegal drugs. These prohibitions in some instances are very different from those of international students' home countries. Similarly, the university only recruits those scholars and administrative personnel whose lifestyles align with the 
university's traditional values and Christian spirit. This demand for a particular lifestyle has presented challenges to diversifying its international faculty and students. The current President noted in his interview:

I think we are rumbling with the behavior of international students on campus. You know if you are used to your home community of drinking alcohol and smoking, then how do you manage that in a campus community that does not favor smoking or drinking alcohol. Some of those behavior issues lead to resistance.

A senior administrator agreed, noting that attracting international students and faculty "is not easy because of the university's tradition and culture."

Furthermore, internationalization implies a transformation of people's behavior and attitude. A fundamental attitudinal barrier to behavioral change at the university is that of responsibility displacement, or the attitude that "internationalization is their job, not mine." A senior faculty member explained this barrier: "We need everyone buying into the fact that if we have international students, changes must be made in all the different aspects of the school - housing, support services, curricula, billing, financial aid, scholarship opportunities, etc." She continued, "but they are not in place at the same time." She then described the consequences of not having everyone on campus recognize his or her role in supporting internationalization: "If we do not convince everyone on campus that this is the way to go, that the future of our university depends on this, it won't happen." An administrator stated that: "Our Vice President personally likes to call internationalization 'disruptive innovation.' We are moving at a rapid pace, and when you do that, it can make change uncomfortable. People fear change, most people are afraid of how it might look."

In addition to the internal cultural and attitudinal barriers, interviewees also identified some external barriers. Geographic location, for instance, is an important barrier and challenge to its internationalization. The rural environment and small campus in the Midwest United States were mentioned by many. A senior faculty member commented, "We believe our location is also an impediment to growth. The university is a very small, rural community. This does not attract students used to living and studying in large cities." The current President agreed, noting, "International students can feel isolated unless they quickly make American friends, or buy cars in their second year of study as we are in a rural area."

Another obstacle is weak branding of the university in the global arena. The perceived lack of a global reputation has brought challenges to the recruitment and retention of international students, especially those from Asian cultures which cherish rankings and big names. Many students who graduate from the University Pathways program prefer to choose big name universities for their degree programs of study. This is one of the frustrations the university has faced. This lack of a strong reputation for internationalization also causes faculty and administrators to feel diffident about promoting the university to a global population and building collaboration with global partners.

Besides its location and branding, the political macro-environment is also adversely impacting institutional approaches to internationalization. Some of the interviewees mentioned that the administration under President Trump was problematic for the university's future internationalization. The current President commented:

President Trump seems to be unwelcoming of everybody in terms of how he wants to build the wall with Mexico and wants only American students. Also, visa restrictions on inbound student/staff and U.S. visa processes are frustrations of internationalization.

A senior faculty member expressed similar concerns:

President Trump has a negative impact on internationalization of universities/colleges. There is a clear division in our citizens-those that embraced the "America first" slogan to mean we don't need to like, be nice to, accommodate foreigners in our nation, or even accept Americans who are people of color. Then we have those that see diversity of the population and international efforts as essential for the future of our nation. So far, the college constituents (former students, alumni, special donors, members of the Board of Trustees) have been in favor of the internationalizing efforts on campus. Yet, many of them are firm Trump supporters, so, I don't know how they will respond in the next few years to internationalizing efforts. The attitude of those who supported Trump's "America first" slogan is detrimental to internationalizing anything.

In sum, cultural challenges to the university's internationalization include internal policies and actions, such as the Christian-based lifestyle regulations, attitudinal barriers to organizational change, as well as external challenges, such as its remote location, weak branding, and American policy. 


\subsubsection{Governance and Structural Barriers}

For this study, governance is concerned with the structures, procedures, and communications for decision making, accountability, control, administration, communication, and codes of conduct for internationalization. It is expressed through legislation, structure, policies, regulation by-laws, and informal norms. Three barriers and challenges to internationalization have been identified in the areas of governance. These are decision making protocols, structure, and communication.

An issue that affects internationalization at this university and most other HEIs is the lack of independence and authority of the leadership to make and implement decisions. Thus, internationalization efforts become immersed in bureaucracy. At Greenville University, there are many governing bodies, such as the Board of Trustees, President's Cabinet, President's Council, Dean's Council, and many faculty committees in governance. Such a system restricts individual leaders' options to address the challenges of an evolving environment. Meanwhile, decision making structures are further complicated by a diffusion of authority across different entities. One frustration expressed by a senior administrator was the lack of control over the decision making and hiring of academic personnel to support internationalization. This statement was supported by interviews and observations suggesting that the non-academic leadership and staff at the university felt they had very little control in the area of academic support personnel and that there were many student and faculty mobility issues that required professional academic expertise, including hiring of language faculty, but they had little support from the academic units.

Besides the challenge of a less than ideal decision-making structure, the lack of clear or supportive regulatory frameworks at this university also limits leadership's capacity to implement internationalization effectively and efficiently. Expectations of leadership and authority are often not as clearly defined in HEIs as they are in other organizations (Hudzik, 2015), and leaders are often in a position where they must persuade rather than mandate change. Such an organizational reality can present significant challenges to rapid innovation. Instead, changes such as internationalization require coalition building and some degree of coordination for clarity of purpose and direction (Hudzik, 2015). In the view of participants in this research, Greenville University, like most HEIs, has the drawbacks of a loosely coupled organization (Weick, 1991). For example, a faculty member noted that:

A barrier to successful internationalization of the student body was the reality that the international students, already unfamiliar with U.S. colleges and customs, had to work with multiple offices such as housing, student success, records, and others without a clear coherence and coordination among them.

The current President contrasted the coordinated support students received in the University Pathways program with the support provided to international students in the traditional undergraduate program, as he expressed the need for a coordinator of service in order to fully implement internationalization:

With our University Pathways program, we have [Liz] (pseudonym). She is very motherly to the students. She cares very deeply about international students. It is a big culture shock, when they leave University Pathways for the main campus, where there are fewer support structures. So, at times students kind of fall between the gaps.

A senior administrative officer also described an additional implementation administrative challenge: "Our greatest area of challenge has been in adapting new admissions and marketing situations globally...combined with getting approval [for] credit articulation in a timely manner within the university." One administrator noted:

An obstacle to internationalization is the rigidity of the academic curriculum, posing difficulties for students from outside the university to find comparable courses that will transfer and apply towards their degrees. Even different units/schools' credit articulation at some levels could cause barriers for increasing the retention rate of international student at the university, such as grades and credit transfers, class registration timelines, payment timelines.

A final obstacle and challenge for internationalization at this university within this category is an observable lack of clear and effective communication channels. Butler (2016) argued that campus leaders have the freedom to be directive on many issues, but that there is some risk in taking advantage of this freedom because when faculty and staff are left out of decision making, their support is often lacking. The lack of effective communication influenced how internationalization was framed on campus at the university. For example, a faculty member stated that: "One of the barriers is we have not had any conversations with the administration as far as the study abroad program is concerned. I think that this is a big gap of communication." He added that: "Communication is not always smooth between different offices." Another senior department chair also noted: "We don't always communicate those international programs with high possibilities for success to the campus community. The 
senior leaders could give a higher profile to international programs so that the entire campus is more engaged in the internationalization efforts." A senior faculty member also expressed her worries about communication: "If we don't convince everyone on campus that this is the way to go, that the future of our university depends on the internationalization, it won't happen."

\subsubsection{Human Resource Barriers}

The third major barrier mentioned by the interviewees was a limitation of human resources to serve internationalization. At this university, one issue is the lack of international and intercultural background of faculty and administrative support staff, and also the "lack of faculty interest and involvement in internationalization" (Knight, 2005, p. 75). Without sufficient numbers of qualified individuals, the university's faculty and administrative support staff are working extra hours. An administrator stated that, "The university needs to hire more staff to support student services," and a senior faculty expressed concern that few human resources were dedicated to international efforts. Another administrator agreed, noting that: "The biggest challenge is not having enough manpower to accomplish all the positive changes and projects we would like to have in place at this very moment."

In part, the insufficiencies at the university in relation to internationalization are linked to the lack of enough faculty and staff to work in this area, as well as the insufficient knowledge and skills of existing faculty and staff. Also concerning, are the disinterest and reluctance on the part of some of the faculty at the university to attempt to meet the educational needs of their international students. A senior administrative officer mentioned that there were faculty who resisted internationalization, especially because of the challenges of teaching students struggling with language issues in the classroom. An administrator agreed:

The university students and faculty do express some resistance to international activities on campus. This resistance can arise from concerns by faculty as well as by academic units that they do not have the experience and skills necessary to engage internationally in a quality manner or in international subject matter.

In sum, when human resources are either insufficient or when personnel have negative perceptions on internationalization, these issues become a barrier to the process.

\subsubsection{Financial Barriers}

Many campuses face the challenge of insufficient funding, and the success of every academic innovation hinges on the availability of adequate resources. At many institutions, insufficient funding for faculty engagement in internationalization is exacerbated by the marginal status of international activities and programs on most campuses (Green \& Olson, 2008). Internationalization becomes real and legitimate when the institution devotes human and financial resources to achieving expressed goals. Similar to institutions worldwide, conditions of financial distress or constraint at the university were viewed as a significant barrier to internationalization. A department chair stated that dollars were always tight for internationalization:

The challenges are financial certainly because to define internationalization properly means dollars, and that is a big challenge. So right now, the challenge is that the program is largely self-supporting, meaning that the students are required to bring dollars with them. Then those dollars can be used to further student recruitment and to give student support services to those students. One of our challenges is to find external sources of funding for internationalization efforts.

Another administrator also noted that:

A significant barrier to internationalization of the university would be the lack of American students going to study abroad. Whether that lack is related to finances or to interest is unknown. Normally students willingly participate in cultural activities produced for the entire campus, so perhaps the reluctance is due to the financial hurdle American students could be facing if they study abroad, and the university does not invest money to support study abroad program.

In addition, several participants commented about the different priorities and interests that take away the financial support for internationalization efforts at the university. As one senior faculty stated: "Resources are limited at the college. As a result, money is limited for any endeavor within the college, and internationalization efforts have not gained the priority yet."

In summary, the major obstacles facing internationalization at the university fall into four categories: cultural traits, organizational governance and structure, human resources, and finances. Individuals also mentioned a few additional barriers including language difficulties of international students and the challenges of infusing 
internationalization into all aspects of campus life.

\section{Implications and Conclusions}

The motivations and rationales driving internationalization vary from institution to institution. Differing and competing motivations and rationales contribute to both the complexity of the international dimension of education and the substantial contributions that internationalization makes. In spite of the complexity of individual rationales or a set of motivations, it is of fundamental importance for an institution to be very clear in articulating its motivations for internationalization, as policies, programs, strategies, and outcomes are all linked and guided by explicit and even implicit rationales (Knight, 2004). A clear understanding of motivation also collectively encourages a comprehensive and strategic institutional approach to internationalization and encourages a wide range of actions that must involve all institutional missions (Hudzik, 2015). Three main motivations drive Greenville University's internationalization: expanding its influence on a broader audience, enhancing the quality of teaching and learning, and diversifying its revenue. To a large degree, these influence the priority actions of the institution and influence policies and resource allocations.

This study noted that multiple factors made internationalization at Greenville University increasingly difficult. These include the institution's cultural traits, governance and administrative structures, and inadequate human and financial resources. Specifically, the institution's Christian culture, rural location, the lack of clear communication channels, and scarce budget and human resources are the most critical barriers inhibiting internationalization at the university. Institution-wide internationalization requires the university to address the barriers and challenges on both the organizational and individual levels. As Childress' (2009) research suggests, successful implementation only begins with the strategic plan and getting action underway; the real work is in the on-going confrontation of expected and unexpected barriers to achieving results. Recognizing and dealing with challenges and barriers to organizational change are essential to moving from concept to action to results with respect to institutional internationalization.

\section{References}

Aigner, J., Nelson, P., \& Stimpfl, J. (1992). Internationalizing the university: Making it work. Springfield, VA: CBIS Federal.

Alladin, I. (1992). International co-operation in higher education: the globalization of universities. Higher Education in Europe, 17(4), 4-13. https://doi.org/10.1080/0379772920170402

Alles, P. D. (2013). Internationalization strategies of liberal arts institutions in a globalizing economy (Doctoral dissertation). Available from ProQuest Dissertations \& Theses Global (Order No. 3552602).

Altbach, P. G. (2008). Globalization and forces for change in higher education. International Higher Education, 50, 2-4. https://doi.org/10.6017/ihe.2008.50.7997

Arabkheradmand, A., Shabani, E. A., Zand-Moghadam, A., Bahrami, H. S., Derakhshesh, A., \& Golkhandan, A. R. (2015). An introduction to the internationalization of higher education: Essential topics. Lanham, MD: University Press of America, Inc.

Bonfiglio, O. (1999). The difficulties of internationalizing the American undergraduate curriculum. The Journal of Studies in International Education, 3(3), 13-18. https://doi.org/10.1177/102831539900300202

Bostrom, C. A. (2007). Diffusion of internationalization in Turkish higher education: A comparative case study at Ankara University and Gazi University (Doctoral dissertation). Available from ProQuest Dissertations \& Theses Global. (Order No. 3309202)

Brandenburg, U., \& de Wit, H. (2011). The end of internationalization. International Higher Education, 62, 15-17. https://doi.org/10.6017/ihe.2011.62.8533

Butler, D. C. (2016). Comprehensive internationalization: Examining the what, why, and how at community colleges (Doctoral dissertation). Available from ProQuest Dissertations \& Theses Global. (Order No. 10111570)

Childress, L. K. (2009). Internationalization plans for higher education institutions. Journal of Studies in International Education, 13(3), 289-309. https://doi.org/10.1177/1028315308329804

Childress, L. K. (2010). The twenty-first century university: Developing faculty engagement in internationalization (32nd ed.). New York, NY: Peter Lang.

De Wit, H., \& Knight, J. (Eds.), (1999). Quality and internationalization in higher education. Paris, France: Organisation for Economic Co-operation and Development. 
De Wit, H. (2000). Changing rationales for the internationalization of higher education. Internationalization of higher education: An institutional perspective. Bucharest, Romania: Centre Européen pour l'Enseignement Supérieur. United Nations Educational, Scientific and Cultural Organization. https://doi.org/10.6017/ihe.1999.15.6477

De Wit, H. (2002). Internationalization of higher education in the United States of America and Europe: A historical, comparative, and conceptual analysis. Westport, CT: Greenwood Press.

De Wit, H. (2011a). Globalisation and internationalisation of higher education. International Journal of Educational Technology in Higher Education, 8(2), 241-247.

De Wit, H. (Ed.). (1995). Strategies of internationalization of higher education. Amsterdam, Netherlands: European Association for International Education.

Deardorff, D. K. (2012). Looking to the future: Leadership perspectives on internationalization-A synthesis. AUDEM: The International Journal of Higher Education and Democracy, 3, 71-80.

Egron-Polak, E. (2011). Monitoring internationalization of higher education. International Higher Education, 63, 2-3.

Egron-Polak, E., \& Hudson, R., (2014). Internationalization of higher education: growing expectations, fundamental values: IAU 4th Global Survey. Paris, France: International Association of Universities.

Green, M. F., \& Olson C. L. (2008). Internationalizing the campus: A user's guide. Washington, DC: American Council on Education.

Hudzik, J. K. (2015). Comprehensive internationalization: Institutional pathways to Success. New York, NY: Routledge. https://doi.org/10.4324/9781315771885

Knight, J. (1994). Internationalization: Elements and checkpoints (CBIE research paper no. 7). Ottawa, Canada: Canadian Bureau for International Education.

Knight, J. (1997). Internationalization of higher education: A conceptual framework. In J. Knight, \& H. de Wit (Eds.), Internationalization of higher education in Asia Pacific countries (pp. 5-19). Amsterdam, Netherlands: European Association of International Education.

Knight, J. (1999b). Internationalisation of higher education. Quality and internationalisation in higher education. Paris, France: Organisation for Economic Cooperation \& Development

Knight, J. (2004). Internationalization remodeled: Definition, approach, and rationales. Journal of Studies in International Education, 8(1), 5-31. https://doi.org/10.1177/1028315303260832

Knight, J. (2005). IAU global survey report. Paris, France: International Association of Universities.

Knight, J. (2006b). Internationalization: Concepts, complexities and challenges. In J. J. F. Forest, \& P. G. Altbach (Eds.), International handbook of higher education (pp. 207-227). Dordrecht, Netherlands: Springer. https://doi.org/10.1007/978-1-4020-4012-2_11

Knight, J. (2009). New developments and unintended consequences: Whither thou goest, internationalization? In R. Bhandari, \& S. Laughlin (Eds.), Higher education on the move: New developments in global mobility (Global Education Research Reports) (pp. 113-125). New York, NY: Institute for International Education.

Knight, J. (2011). Five myths about internationalization. International Higher Education, 62, 14-15.

Knight, J., \& de Wit, H. (1995). Strategies for internationalisation of higher education: Historical and conceptual perspectives. In H. de Wit (Ed.), Strategies for internationalisation of higher education: A comparative study of Australia, Canada, Europe, and the United States of America (pp. 5-32). Amsterdam, Netherlands: European Association for International Education.

Knight, J., \& de Wit, H. (Eds.). (1997). Internationalization of higher education in Asia Pacific countries. Amsterdam, Netherlands: European Association for International Education.

Knight, J., \& de Wit, H. (Eds.). (1999). Quality and internationalization in higher education. Paris, France: Organisation for Economic Co-operation and Development.

O’Carroll, C. (2012, April 26). New body sees value of research. The Irish Times (p. 12).

O'Malley, D. (2015). Internationalization of higher education: A case study of Trinity College Dublin (Doctoral dissertation). Available from ProQuest Dissertations \& Theses Global. (Order No. 3710664)

Robson, S. (2011). Internationalization: A transformative agenda for higher education? Teachers and Teaching: 
Theory and Practice, 17(6), 619-630. https://doi.org/10.1080/13540602.2011.625116

Saat, A. (2007). Internationalization of higher education: Preparation, policy, implementation and recognition. US-China Education Review, 6(5), 1-9.

The University Strategic Plan. (2016). Publication information blinded.

Van der Wende, M. C. (1996). Internationalising the curriculum in Dutch higher education: An international comparative perspective (Unpublished doctoral dissertation). Utrecht University, Netherlands.

Van Vught, F. A., van der Wende, M. C., \& Westerheijden, D. F. (2002). Globalisation and internationalization: Policy agendas compared. In J. Enders, \& O. Fulton (Eds.), Higher education in a globalizing world. International trends and mutual observations (pp. 103-121). Dordrecht, Netherlands: Kluwer. https://doi.org/10.1007/978-94-010-0579-1_7

Weick, K. E. (1991). Educational organizations as loosely coupled systems. In M. W. Peterson, E. E. Chafe, \& T. H. White (Eds.), Organization and governance in higher education: An ASHE Reader (pp.103-117). Needham Heights, MA: Simon \& Schuster.

\section{Copyrights}

Copyright for this article is retained by the author(s), with first publication rights granted to the journal.

This is an open-access article distributed under the terms and conditions of the Creative Commons Attribution license (http://creativecommons.org/licenses/by/4.0/). 